\title{
Die Firma im internationalen Rechtsverkehr
}

Zum Kollisionsrecht der Firma unter besonderer Berücksichtigung des Rechts der Europäischen Union

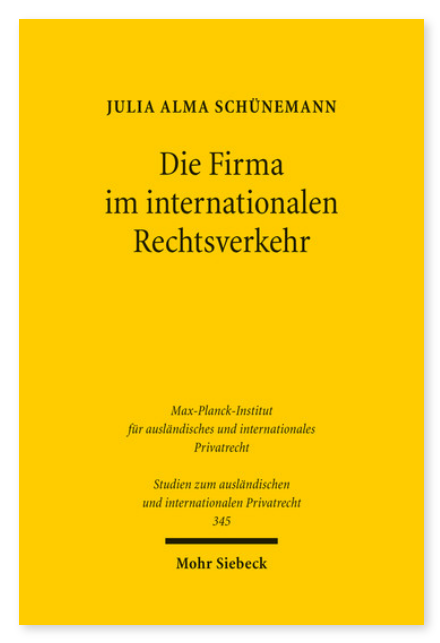

2016. XXVII, 293 Seiten. StudIPR 345

ISBN 978-3-16-154152-0

DOI 10.1628/978-3-16-154152-0

eBook PDF 79,00€

ISBN 978-3-16-154151-3

fadengeheftete Broschur 79,00€
Angenommen, eine englische Limited beantragt, im deutschen Handelsregister unter ihrer Firma »Auskunft Limited« eingetragen zu werden. Einer deutschen Gesellschaft würde die Eintragung unter einer entsprechenden Firma wegen Verstoßes gegen den Grundsatz der Firmenunterscheidbarkeit verweigert werden. Aber gilt dies auch für die englische Limited? Julia Alma Schünemann geht dieser Frage nach und untersucht, wie das maßgebliche Firmenstatut zwischen privaten Partei- sowie staatlichen und europäischen Ordnungsinteressen zu bestimmen ist. Dazu arbeitet sie die Grenzen zwischen Internationalem Privatrecht und Internationalem Öffentlichen Recht heraus und entwickelt ein System, wie international zwingendes Recht in das allseitige Verweisungssystem des IPR auf Grundlage einer modifizierten Interessenlehre integriert werden kann. Dabei kommt sie zu dem Ergebnis, dass eine gesellschaftsrechtliche Anknüpfung, anders als in bisherigen Gesetzesvorschlägen, auch im Lichte der Europäischen Grundfreiheiten weder geboten noch zweckmäßig ist.

Julia Alma Schünemann Geboren 1986; Studium der Rechtswissenschaft an der Universität zu Köln; seit 2010 Wissenschaftliche Mitarbeiterin am Institut für internationales und ausländisches Privatrecht, Universität zu Köln; 2015 Zweites Staatsexamen.
Jetzt bestellen:

https://mohrsiebeck.com/buch/die-firma-im-internationalen-rechtsverkehr-9783161541520?no_cache=1 order@mohrsiebeck.com

Telefon: +49 (0)7071-923-17

Telefax: +49(0)7071-51104 